\title{
Transaxillary Surgical Ligation of Patent Ductus Arteriosus in Paediatric Group of Patient
}

\author{
Md Zahidul Islam, Kazi Abul Hasan, Khondokar Shamim Shahriar Ziban Rushel, Shahriar Moinuddin, \\ Saiful Islam Siraji, Md Faizul Islam, Shahnaz Ferdous, Md Azizul islam \\ Department of Cardiac Surgery, NICVD, Dhaka
}

Key words: congenital heart

disease, Patent

ductus

arteriosus,

Transaxillary

approach.

\begin{abstract}
:
Background: Patent ductus arteriosus is a frequent congenital anomaly with left to right shunt. The aim of this study is to assess 3 years' experience of transaxillary approach in surgical ligation of patent ductus arteriosus.

Methods: In three years from July 2015 to September 2017, 46 patients underwent in surgical ligation of patent ductus arteriosus through transaxillary approach. All patients had undergone elective operation. Intra operative and post-operative data were analyzed and follow up after 1 month and 3 years.

Results: There were 18 male (39\%) and 28 female (61\%). Their age range was from 5 months to 10 years months (mean $39.2 \pm 24.7$ months) and body weight ranges from $4.5 \mathrm{~kg}$ to $32 \mathrm{~kg}$ (mean $16.05 \pm 6.63 \mathrm{~kg}$ ). There was no mortality or residual patency. Morbidity includes superficial wound infection and chylothorax. All patient discharge on 3rd-5th postoperative day except those who developed chylothorax was discharged after 8 days.

Conclusion: Trans axillary approach for closure of PDA has moved from an alternative incision to a standard posterolateral incision in our experience. It is less traumatic and more cosmetic.
\end{abstract}

(Cardiovasc. j. 2019; 11(2): 114-117)

\section{Introduction:}

Patent ductus arteriosus is one of the most common congenital heart defects accounting for $5-10 \%$ of all congenital heart diseases with left to right shunt and reported incidence in term neonate only 1:2000 life birth. ${ }^{1}$ Due to its haemodynamic consequences and curative result of closure, various methods for closure have been introduced. Indomethacin still been used specially in neonates as a medical methods initiates cessation of shunt. ${ }^{2}$ Percutaneous transcatheter ductal closure has taken most of PDA cases away from surgical intervention. Recent success of video assisted thoracoscopic clipping or ligation has added a new alternate for closure. ${ }^{3}$ However conventional surgical ligation is the ultimate request when other methods fail to achieve cessation of the shunt. Conventional posterolateral thoracotomy incision is still used but it is less cosmetic and more painful and produce bad scar. The current study is designed to assess the outcome of the transaxillary approach in surgical ligation of patent ductus arteriosus.

\section{Methods:}

Between January, 2015 to May, 2018 total 46 patients underwent transaxillary surgical ligation of PDA in National Institute of cardiovascular diseases, Dhaka, Bangladesh. There were 18 male(39\%) and 28 female (61\%). Their age range from 5 months to 10 years months (mean $39.2 \pm 24.7$ months) and body weight ranges from $4.5 \mathrm{~kg}$ to $32 \mathrm{~kg}$ (mean $16.05 \pm 6.63 \mathrm{~kg}$ ). All patients had undergone elective operation. The studied patients had pre and post operative clinical assessment, routine laboratory investigation, chest X -ray, ECG and Echocardiography.

\section{Operative technique:}

All patients underwent operation after they had been anesthetized and intubated. A radial or femoral arterial line was used to continuously

Address of Correspondence: Dr . Md Zahidul Islam, Department of Cardiac Surgery, National Institute of Cardiovascular Diseases, Dhaka, Bangladesh. Email- zahidcts@gmail.com

C) 2018 authors; licensed and published by International Society of Cardiovascular Ultrasound, Bangladesh Chapter and Bangladesh Society of Geriatric Cardiology. This is an Open Access article distributed under the terms of the CC BY NC 4.0 (https:// creativecommons.org/licenses/by-nc/4.0). 
monitor arterial pressure and a pulse oximeter was used to monitor oxygen saturation. The patient were placed in right lateral position into the left hand over the head.

The patient were firmly stabilized in this position into sand bags or pads at the front, back and under the chest, left arm was elevated and fixed, optimally exposing the axillary area. A vertical incision extends between the anterior and posterior axillary fold. The incision is about 4-6 $\mathrm{cm}$ large from apex of axilla and over the upper border of the 5th rib (Fig. 1).

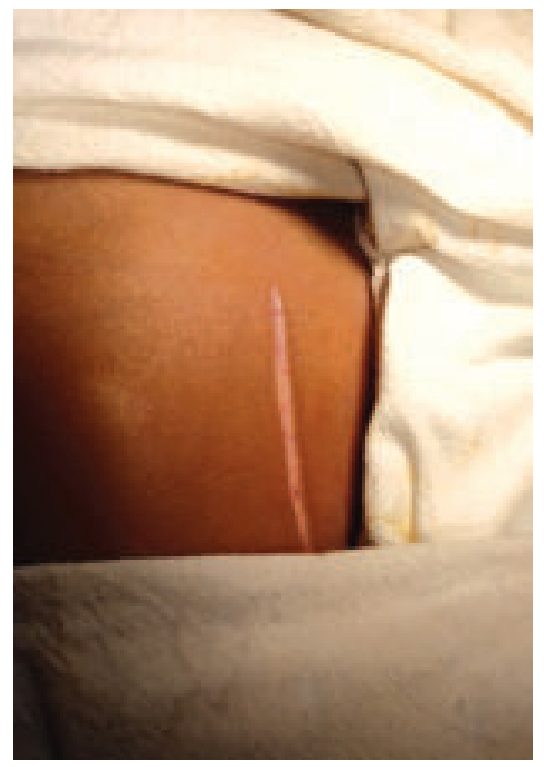

Fig.-1: Incision for PDA ligation through trans axillary approach.

The incision cuts down to the axillary fascia, reading to fleshy fibers of the upper digits of the serratus anterior muscle. At this stage it is quite easy to identify $3^{\text {rd }}$ rib and $4^{\text {th }}$ rib. Intercostal muscle were divided with diathermy along the upper border of the $4^{\text {th }}$ rib and the chest cavity was entered through $3^{\text {rd }}$ intercostal space. Two rib retractors were inserted at right angle to each other and open slowly with simultaneous dividing intercostal muscle anteriorly and posteriorly.

It is important to disconnect patient from the ventilator during entering the pleura to avoid lung injury. Once pleural cavity is entered assessment of anatomy is mandatory followed by identifying the ductus lying between aortic arch, descending thoracic aorta laterally, the left pulmonary artery tree medially. Parietal pleura are opened and the ductus is dissected as connective tissue around it, multiple ligation and transfixation of PDA were done (Fig. 2).

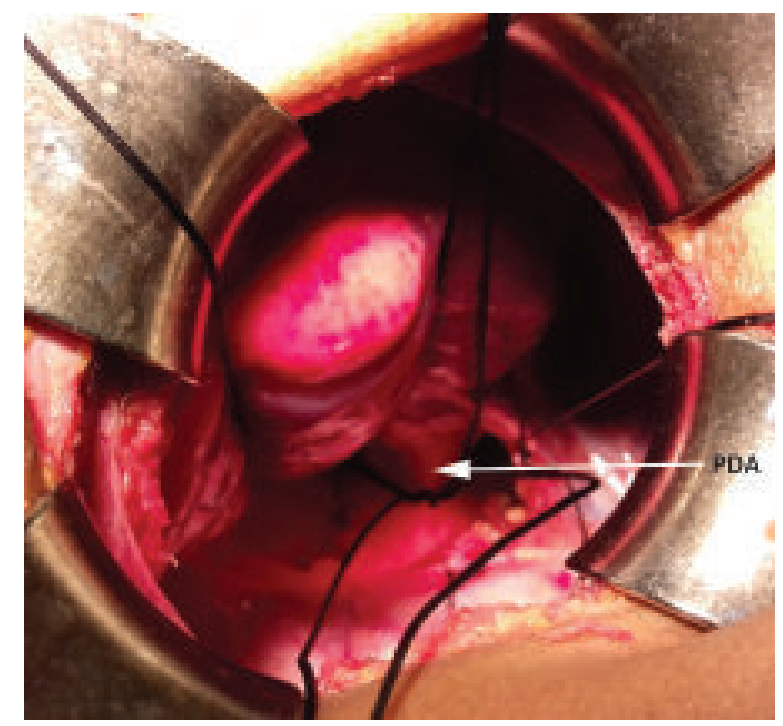

Fig.-2: Ligation of PDA.

At the time of initial aortic end ligation systolic blood pressure is lowered down to $50-60 \mathrm{~mm}$ of $\mathrm{Hg}$ to prevent rupture or tear of PDA. During this procedure left vagus and left recurrent laryngeal nerve were properly identified and due care were taken for prevention of their injury. After proper hemostasis and closure of pleural flap, chest closure were done with or without chest drainage tube. Fig. 3 and 4

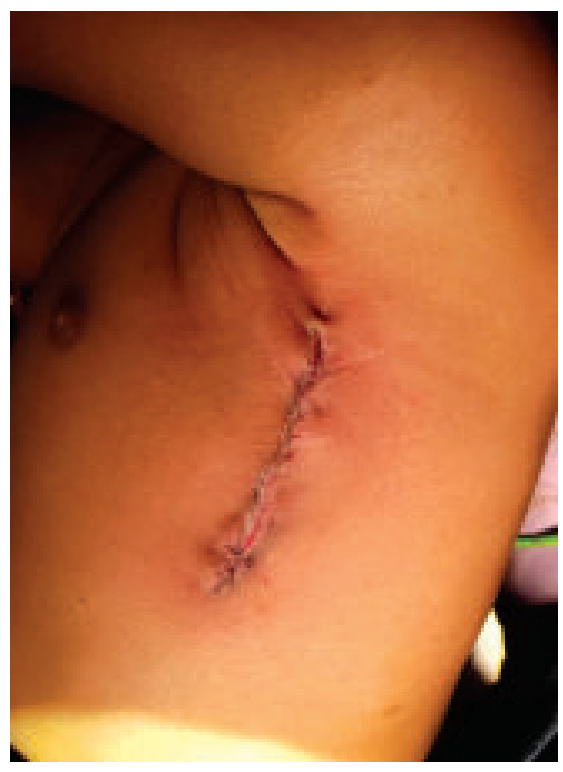

Fig.-3: Chest closure without drainage tube. 


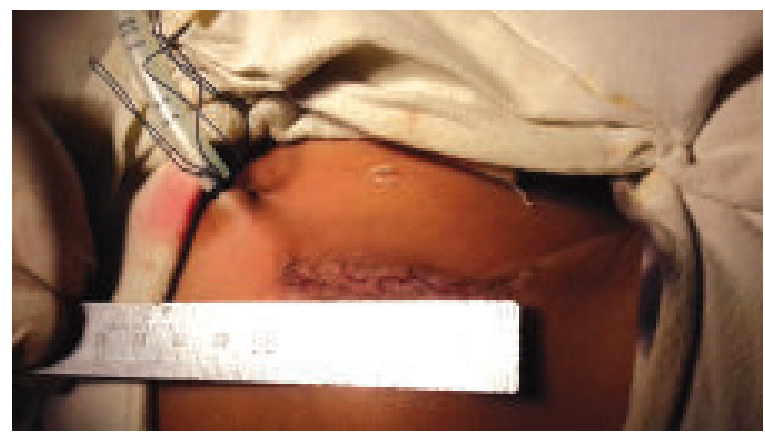

Fig.-4: Chest closure with drainage tube.

All efforts were done to re- inflate lungs before closure of chest. Most of the patients were extubated 2-4 hours after elective ventilation and few were on operation table. In post-operative period, chest tube were removed after 24-36 hours. Patients were discharged after 3-5 days with post-operative follow up echo color Doppler and called for follow up after 1 month and 1 year.

\section{Results:}

In three years, 46 patients underwent transaxillary approach in surgical ligation of patent ductus arteriosus. There were 39\% male and $61 \%$ female. Their age range was from 5 months to 10 years.

\section{Table-I}

Age and sex distribution of the study population $(N=46)$.

\begin{tabular}{lccccc}
\hline & 5 months -1yrs & 1-3yrs & 3-5yrs & 5-10yrs & Total \\
\hline Male & 3 & 4 & 8 & 3 & 18 \\
Female & 4 & 7 & 13 & 4 & 28 \\
\hline Total & 7 & 11 & 21 & 7 & 46 \\
\hline
\end{tabular}

All had undergone elective surgical operation. The main indication was recurrent chest infection (65\%), failure to thrive (35\%), Right ventricular failure (5\%).

\section{Table-II}

Indications of surgery in study population with PDA.

\begin{tabular}{lcc}
\hline Indications of surgery & Number & Percentage \\
\hline Recurrent RTI & 25 & $54.34 \%$ \\
Failure to thrive & 15 & $32.6 \%$ \\
RV failure & 1 & $2.17 \%$ \\
\hline
\end{tabular}

On echocardiography $15 \%$ are small PDA, rest of them were moderate to large PDA. $85 \%$ patient had moderate to severe pulmonary hypertension.

Table-III

Echocardiographic data regarding PDA size.

\begin{tabular}{lcc}
\hline PDA size $(\mathrm{mm})$ & Number & Percentage \\
\hline $3.0-4.9$ & 08 & $17.39 \%$ \\
$5.0-6.9$ & 22 & $47.82 \%$ \\
$7.0-9.9$ & 13 & $28.26 \%$ \\
$>10.0$ & 03 & $06.52 \%$ \\
\hline
\end{tabular}

\section{Table-IV}

Echocardiographic data regarding pulmonary hypertension of the study population.

\begin{tabular}{lcc}
\hline Pulmonary HTN & Number & percentage \\
\hline Mild & 7 & $15.21 \%$ \\
Moderate & 15 & $32.60 \%$ \\
Severe & 16 & $34.78 \%$ \\
\hline
\end{tabular}

The average operative time was 35-60 minutes. $10(21.7 \%)$ patients were extubated on operative table and 36(78.1\%) patients required elective mechanical ventilation for $2-4$ hours. $18(39.1 \%)$ patients did not require chest drainage tube and remaining $28(60.9 \%)$ patient's chest drainage tube were removed after 24 hours except one who developed chylothorax that managed conservatively and drain tube were removed on $6^{\text {th }}$ post-operative day. The total blood loss ranges from 10-30 $\mathrm{ml}$. There was no early wound dehiscence, lung complications. ICU stay were 12-48 hours (mean 19.4 \pm 8.4 hours), hospital stay range from $3-8$ days (mean $4.7 \pm 1.4$ days).

\section{Discussion:}

The first description of surgical ligation and division of PDA through posterolateral thoracotomy was given by Robert E. Gross in 1939. 4,5 The first transaxillary thoracotomy for closure of PDA was done by Denis Browne in 1952. ${ }^{2}$ Percutaneous trans catheter ductal closure using Raskind double umbrella or coil device in closure of PDA cases away from surgical intervention. ${ }^{7}$ Subsequently over many decades several methods have been introduced for interruption of PDA. ${ }^{8}$ 
Posterolateral thoracotomy is considered the standard incision for PDA ligation. It is long incision in comparison other incision. Therefore, it is not reasonable for cosmetic point of view. It is a muscle cutting incision (Latissimus dorsi and serratus anterior) with probability of degree of weakness due to fibrosis of these muscles. Muscle sparing posterolateral thoracotomy incision to avoid splitting or cutting of the serratus anterior muscle with subsequent winging of the scapula in same circumstances. Sub axillary (horizontal) thoracotomy is a combination of muscle sparing and cutting incision. ${ }^{9}$

Transaxillay approach has been used for many years. ${ }^{10}$ Trans axillary vertical incision is modification to one of those skin creases of the axilla above the $4^{\text {th }}$ rib which is hidden by upper arm. It does not cut across any muscle. The 4 th and $3^{\text {rd }}$ digits of the serratus anterior can be split up to reach down to the upper border of the $4^{\text {th }}$ rib. Facing the PDA to the incision is quite considerable advantage of this surgical technique. ${ }^{11}$

It is difficult for the assistant to see operative details. Through the procedures assistants complain of seeing nothing of the operative technique was quite remarkable.

In this technique, less surgical manipulation is an advantage in the subsequent reduction of surgical trauma and blood loss. We did not have any surgical emergency to extend this incision to control unseen event that needed to extent the incision posteriorly.

Chest closure without drainage following PDA ligation is safe and effective and less postoperative complication. ${ }^{12}$ In our study, about one third of the patients, chest were closed without chest drainage tube.

In this study, one patient developed chylothorax that was noticed first operative day and treated conservatively, no early or late mortality. One patient developed superficial wound infection but no mechanical dehiscence, lung collapse, recurrent laryngeal nerve injury that is similar to Abdullah's study. ${ }^{11}$

Transaxillary approach produced no unsightly scar and keloid in our experience over 3 years follow up, if developed upper arm would hide it and this is one of the advantages of this approach, there was no residual shunt, dehiscence, hospital re admission in the studied patients.

\section{Conclusion:}

Transaxillary approach for closure of PDA is an effective and safe alternative incision to a standard posterolateral incision in our experience. It is less traumatic and more cosmetic.

\section{Conflict of Interest - None.}

\section{References:}

1. Schneider DJ, Moore JW. Patent ductus arteriosus. Circulation 2006;114:1873-18829(Pub Med)

2. Hammerman C, Glaser J, Kaplan M, Schimmel MS, Ferber B, Eidelman AI. Indomethacin tocolysis increases postnatal ductus arteriosus severity. Pediatrics 1998 Nov; 102 (5):E563.

3. Ho AC, Tan PP, Yang MW, Yang CH, Chu JJ, Lin PJ, et al. The use of multiple transesophageal echocardiography to evaluate residual patent ductus arteriosus during videoassisted thoracoscopy in adults. Surg Endosc 1999 Oct; 13 (10):975-979.

4. Gross RE, Hubbard JP. Landmark article Feb 25; 1939: Surgical ligation of a patent ductus arteriosus. Report of first successful case. By Robert E, Gross and John P. Hubbald. JAMA 1984; 251: 1201-1202.

5. Blalock A. Operative closure of the patent ductus arteriosus. Surg Gynecol Obstet 1946; 82:112.

6. Gray DT, Fyler DC, Walker AM, Weinstein MC, Chalmers TC. Clinical outcomes and costs of transcatheter as compared with surgical closure of patent ductus arteriosus. NEngl J Med 1993; 329: 1517-1523.

7. Grifka RG, Fenrich AL, Tapio JB. Transcatheter closure of patent ductus arteriosus and aorto-pulmonary vessels using non-ferromagnetic Inconel MReye embolization coils. Cath Cardiovasc Interv 2008 .Nov 1;72(5):691-695.

8. Kan CD, Luo CY, Yang YJ. Application of pusher in mini invasive patent ductus arteriosus ligation. J Card Surg 2001;16:252-254.

9. Yan D, Xie Q, Zhang Z, Gu C, Kawada S. Surgical treatment of patent ductus arteriosus (PDA) through mini subaxillary extrapleural approach. Ann Thorac Cardiovas Surg 1999 Aug; 5 (4):233-236.

10. Hawkins JA, Minich LL, Tani LY, Sturtevant JE, Orsmond GS, McGough EC. Cost and efûcacy of surgical ligation versus transcatheter coil occlusion of patent ductus arteriosus. Journal of Thoracic and Cardiovasular Surgery 1996 Dec; 112 (6):1634-1638.

11. Abdallah MS. Five Years Experiences in Trans-axillary Surgical Ligation of Patent Ductus Arteriosus. Journal of Egyptian society of cardiothoracic surgery. Jul- Dec 2008; 16(3-4): 75-81.

12. Kebba N, Mwambu T, Oketcho M, Izudi J, Obuku EA. Chest closure without drainage after open patent ductus arteiosus ligation in Ugandan children: A non blinded randomized control trail. BioMed Central surgery 2016;16(69):1-7. 